\title{
Konya ilinde büllöz hastalıklar: 93 olgu üzerine bir çalıșma
}

\author{
Bullous disorders in Konya: A study of 93 cases
}

\section{Munise Daye, İnci Mevlitoğlu, Sarenur Esener \\ Necmettin Erbakan Üniversitesi Meram Tıp Fakültesi, Deri ve Zührevi Hastalıklar Anabilim Dalı, Konya, Türkiye}

\section{Özet}

Amaç: Büllöz hastalıklar; deri ve mukozaları tutan, doku adezyon moleküllerine karşı spesifik antikorlarla gelişen ya da genetik kalıtımın neden olduğu bir grup hastalıktır. Ülkemizde bu hastalıkları inceleyen detaylı epidemiyolojik çalışma sınırıdır. Bu amaçla Orta Anadolu'da Konya yöresi ve civarında yaşayan büllöz hastalığı olan olguların demografik, klinik, immünopatolojik, tedavi ve takiplerindeki özellikleri sunmaktayız. Gereç ve Yöntem: Çalışmamızda 2006-2012 yılları arasında büll̈z hastalık tanısıyla takip edilmiş olan 93 olgunun verileri retrospektif değerlendirildi. Olgularımızın çoğunluğu pemfigus ve büllöz pemfigoid grubunda olduğu için onlara ait veriler daha detaylı irdelendi.

Bulgular: Çalışmaya dahil edilen 93 olgunun 50'si (\%53,8) kadın, 43'ü (\%46,2) erkekti. Yaş ortalaması 52,9 yıldı. Olgulardan \%37,6'sı pemfigus vulgaris, \%34,4'ü büllöz pemfigoid, \%15'i herediter epidermolizis bülloza, \%4,3'ü dermatitis herpetiformis, \%4,3'ü pemfigus foliaseus, \%2,2'i pemfigus vegetans, \%1,1'i Hailey-Hailey hastalığı \%1,1'i skatrisyel pemfigoid tanısı almıştı. Pemfigus vulgarisin ortaya çıkış yaş ortalaması 45,9 yıldı ve kadınlarda daha fazla görüldü. Pemfigus vulgarisli olgularda hastalık oral mukozadan başladı ve diğer coğrafik bölgelere göre; oral mukoza tutulumu ile başlayan pemfigus vulgarisli olgularda tanı alma süresi daha uzundu. Büllöz pemfigoidin ortaya çıkış yaş ortalaması 70 yıldı ve kadınlarda daha fazla görüldü. Olguların \%12,5'inde hastalık oral mukozadan başladı. Hiçbir olguda eşlik eden otoimmün hastalık saptanmadı. Doksan üç olgunun 25'ine sadece sistemik steroid, 41 'ine sistemik steroid ve adjuvan, 11 'ine sadece adjuvan, 16 'sına sadece lokal tedaviler verildi.

Sonuç: Konya ili ve civarında yaşayan büll̈̈z hastalığı olan olguların demografik, klinik, immünopatolojik, tedavi ve takiplerindeki özellikler sunulmaktadır. (Türkderm 2013; 47: 200-4)

Anahtar Kelimeler: Büllü hastalıklar, pemfigus vulgaris, büllöz pemfigoid, Konya

\section{Summary}

Background and Design: Bullous diseases are a group of disorders caused by specific antibodies against tissue adhesion molecules in the skin and mucosa or by genetic inheritance. There are limited detailed epidemiological studies about bullous disorders in Turkey. In this study, we evaluated the demographic, clinical and immunopathological findings as well as course of the disease and follow-up properties in patients with bullous disorders in the Province of Konya.

Materials and Methods: Ninety-three patients, who were followed up between 2006 and 2012, were included in our study. Since most of the patients were in pemphigus and bullous pemphigoid groups, we investigated data on those patients in more detail.

Results: $53.8 \%$ of patients were female and $46.2 \%$ were male. The mean age was $52.9 .37 .6 \%$ of patients had pemphigus vulgaris, $-34.4 \%$ bullous pemphigoid, - 15\%hereditary epidermolysis bullosa, - $4.3 \%$ dermatitis herpetiformis, $-4.3 \%$ pemphigus foliaceus, $-2.2 \%$ pemphigus vegetans, $-1.1 \%$ Hailey-Hailey disease, and $1.1 \%$ of patients had cicatricial pemphigoid. The mean age of onset of pemhigus vulgaris was 45.9

Yazışma Adresi/Address for Correspondence: Dr. Munise Daye, Necmettin Erbakan Üniversitesi Meram Tıp Fakültesi, Deri ve Zührevi Hastalliklar Anabilim Dall, Konya, Türkiye Tel.: +90 3322237912 E-posta: dr_munise@yahoo.com Geliş Tarihi/Received: 20.12.2012 Kabul Tarihi/Accepted: 21.03.2013

Türkderm-Deri Hastalıkları ve Frengi Arșivi Dergisi, Galenos Yayınevi tarafından basılmıștır.

Turkderm-Archives of the Turkish Dermatology and Venerology, published by Galenos Publishing. 
years. Pemhigus vulgaris, which was most frequently observed in females, started at oral mucosa and the time of diagnosis was longer than in patients in the other geographic regions. The mean age of onset of bullous pemphigoid was 70 years and it was mostly observed in females. In 12.5 of cases, the initial manifestations occured the oral mucosa. None of the patients had a concomitant autoimmune disorder. Twenty-five cases were treated with systemic corticosteroids, 41 cases with systemic corticosteroids and adjuvant drugs; 11 patients received only adjuvant therapy, and 16 patients were administered only local steroids.

Conclusion: We report the demographical, clinical and immunopathological, findings as well as course of the disease and follow-up properties in patients with bullous disorders in the Province of Konya. (Turkderm 2013; 47: 200-4)

Key Words: Bullous disorders, pemhigus vulgaris, bullous pemphigoid, Konya

\section{Giriş}

Büllöz hastalıklar; deri ve mukozaları tutan doku adezyon moleküllerine karşı spesifik antikorlarla gelişen ya da genetik kalıımın neden olduğu bir grup hastalıktır. Otoimmün büllöz hastalıklar, spesifik antikorlarla meydana gelen ayrışmanın subepidermal veya intraepidermal yerleşimine göre iki alt gruba ayrılırlar. Subepidermal otoimmün büllöz hastalıklar grubunda başlıca büllöz pemfigoid (BP), akiz epidermolizis bülloza (AEB), sikatrisyel pemfigoid (SP), pemfigoid gestasyones (PG), lineer immunglobulin $A$ dermatozu (LAD), dermatitis herpetiformis $(D H)$ ve büllöz sistemik lupus eritematozus (BSLE) bulunur. İntraepidermal otoimmün büllöz hastalıklar pemfigus grubu hastalıaklardır. Pemfigus grubu hastalıklar ise pemfigus vulgaris (PV), pemfigus vejetans (PVg), pemfigus foliaseus (PF) pemfigus eritematozus $(P E)$, paraneoplastik pemfigus (PNP), immüglobulin $A$ pemfigusu ve ilaçla indüklenen pemfigus olarak sınıflandırılır ${ }^{1}$. Herediter epidermolizis bülloza (HEB), fiziksel travmaya maruz kalan yerlerde bül gelişimi ile karakterize kalıtımsal deri hastalığıdır ve mekanobüllöz hastalıkların prototipidir2. Hailey-Hailey hastalığı otozomal dominant geçişli, özellikle intertriginöz alanlara yerleşen büller ve erozyonlarla karakterize genodermatozdur ${ }^{3}$.

Çalışmamızda; Konya ilinde tanı alarak takip edilmiş, otoimmün ve/veya herediter büllöz hastalığı olan olguların demografik, klinik, immünopatolojik ve tedavi özelliklerini retrospektif değerlendirdik. Elde ettiğimiz bulgularla ülkemizin önemli bir coğrafik bölgesinden, büllöz hastalıklarla ilgili verilerine katkıda bulunmayı amaçlamaktayız. Olgularımızın çoğunluğu pemfigus ve BP grubunda olduğu için onlara ait veriler daha detaylı irdelenmiştir.

\section{Gereç ve Yöntem}

Çalışmamızda kurumumuzdan alınan etik kurul kararından sonra, 2006-2012 yılları arasında büllöz hastalık tanısıyla takip edilmiş olan
93 olgunun verileri retrospektif değerlendirildi. Çalışmaya polikliniğimiz ve servisimizde düzenli takip edilmiş, tanısını klinik ve histopatolojik ve/veya klinik, histopatolojik, direkt immünofloresan (DiF) bulgularılla koyduğumuz olgular dahil edildi. Dosya bilgilerinde değerlendirilmek istediğimiz bilgilerin çoğunluğuna ulaşamadığımız ve takiplerine düzenli gelmeyen olgular çalışmamıza dahil edilmedi. Olguların, sosyodemografik özellikleri, tanıları, histopatolojik ve DiF bulguları, hastalık başlangıç yaşları ve süreleri, klinik bulguları, eşlik eden sistemik hastalıkları, verilen tedavileri, tedavi altındayken tam iyileşme süreleri, tedaviye bağlı yan etkileri kaydedildi. Hastalıkta tetikleyici olabilecek, stres öyküsü, ilaç öyküsü sorgulandı. Olguların tanısında klinik bulgular, histopatolojik değerlendirme, DiF inceleme kullanıldı. Verilerin özetlenmesinde yüzde (\%) kullanıldı.

\section{Bulgular}

Doksan üç olgunun \%53,8'i kadın, \%46,2'si erkekti. Olguların yaş ortalaması 52,9'du. Kadın olgularda yaş ortalaması 53,4 yıl, erkek olgularda 52,5 yıldı. PV olguların yaş ortalaması 50 yıl, BP'li olguların yaş ortalaması 70 yıldı. En düşük yaş ortalaması 15,4 yıl ile HEB'li olgulardaydı. Olguların demografik özellikleri Tablo 1'de gösterilmektedir. PV'li olgularda hastalık başlangıç yaşı 45,9 yıldı ve hastalık başlangıcından tanıya kadar geçen süre ortalama 16,5 aydı. En erken hastalık başlangıç yaşı ortalama 1 ay ile HEB'li olgulardaydı. Olguların ilk tutulum yerleri ve dağılım alanları Tablo 2'de, 69 olguya histopatolojik inceleme yapılmıştır ve histopatolojik bulguları Tablo 3'te gösterilmektedir. DiF incelemede; PV'li olguların \%57,1'inde epidermal IgG birikimi, \%11,6'sında epidermal IgG ve/veya C3 birikimi saptandı. Olguların \%20'sinde DiF negatifti ve \%11,4'ünde biyopsi yapılamadığı saptandı. PF'li \%50 olguda epidermal lgG ,\%25'inde dermoepidermal IgM, PVg'lı \%50 olguda epidermal lgG birikimi saptandı. C3 birikimi

\begin{tabular}{|c|c|c|c|c|c|c|c|c|c|}
\hline \multirow[b]{2}{*}{ Hastalık } & \multirow[b]{2}{*}{ Kadın } & \multirow[b]{2}{*}{ Erkek } & \multirow[b]{2}{*}{$\mathrm{K} / \mathrm{E}$} & \multirow[b]{2}{*}{ Toplam $(\%)^{*}$} & \multicolumn{2}{|c|}{ Ortalama Yaş } & \multicolumn{2}{|c|}{ Hastalık Başlangıç Yaşı } & \multirow[b]{2}{*}{ Akraba Evliliği } \\
\hline & & & & & Kadın & Erkek & Kadın & Erkek & \\
\hline PV & $21(\% 60)$ & $14(\% 40)$ & $1,5 / 1$ & $35(37,6)$ & 47,7 & 53,6 & 44,6 & 47,8 & 0 \\
\hline $\mathrm{PVg}$ & $2(\% 100)$ & 0 & - & $2(2,2)$ & 56 & - & 52,5 & - & 0 \\
\hline $\mathrm{BP}$ & $20(\% 62,5)$ & $12(\% 37,5)$ & $1,7 / 1$ & $32(34,4)$ & 68,9 & 71,9 & 64,6 & 68,9 & $2(\% 6,3)$ \\
\hline Hailey-Hailey & $1(\% 100)$ & 0 & - & $1(1,1)$ & 62 & - & 55 & - & 0 \\
\hline SP & 0 & $1(\% 100)$ & - & $1(1,1)$ & - & 82 & - & 79 & 0 \\
\hline \multirow[t]{2}{*}{ Bütün olgular } & \multirow[t]{2}{*}{$50(\% 53,8)$} & \multirow[t]{2}{*}{$43(\% 46,2)$} & & \multirow[b]{2}{*}{93} & \multicolumn{2}{|c|}{52,9} & & & \\
\hline & & & & & 53,4 & 52,5 & & & \\
\hline
\end{tabular}

*Kolon yüzdesi 
Tablo 2. Hastalık tutulum ve dağlım yerleri (\%)

\begin{tabular}{|c|c|c|c|c|c|c|}
\hline Hastalık & Yalnız oral mukoza (\%) & Yalnız genital mukoza (\%) & Yalnız deri (\%) & Deri+ Mukoza (\%) & Göz (\%) & Tırnak (\%) \\
\hline PV & $\begin{array}{r}* 20(57,1) \\
10(28,6) \\
\end{array}$ & $\begin{array}{rl}* & 1(2,9) \\
& 1(2,9) \\
\end{array}$ & $\begin{array}{r}* 13(37,1) \\
5(14,3) \\
\end{array}$ & $\begin{array}{l}* 1(2,7) \\
20(57,1)\end{array}$ & - & $4(11,4)$ \\
\hline PF & - & - & $\begin{array}{rl}* & 4(100) \\
& 4(100)\end{array}$ & $\begin{array}{l}- \\
-\end{array}$ & - & - \\
\hline$P \vee g$ & 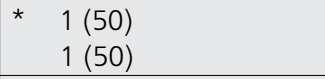 & & $\begin{array}{ll}* & 1(50) \\
& 1(50) \\
\end{array}$ & - & - & - \\
\hline BP & \begin{tabular}{ll|}
$*$ & $4(12,5)$ \\
& $1(3,1)$ \\
\end{tabular} & - & $\begin{array}{l}\text { * } 28(87,5) \\
24(75)\end{array}$ & $-7(21,9)$ & - & \\
\hline EB & $\begin{array}{l}* \quad 1(7,1) \\
0\end{array}$ & - & $\begin{array}{r}\text { * } 13(92,9) \\
9(64,3)\end{array}$ & $\begin{array}{l}* 0 \\
5(35,7)\end{array}$ & - & $\begin{array}{l}* 0 \\
7(50)\end{array}$ \\
\hline $\mathrm{DH}$ & - & - & $\begin{array}{l}\text { * } 4(100) \\
4(100) \\
\end{array}$ & - & - & - \\
\hline Hailey-Hailey & - & - & $\begin{array}{l}* \quad 1(100) \\
1(100) \\
\end{array}$ & - & - & - \\
\hline$S P$ & - & - & - & - & $\begin{aligned} & * 1(100) \\
& 1(100)\end{aligned}$ & - \\
\hline
\end{tabular}

* :ilk tutulum alanları

PV: Pemfigus vulgaris, PF: Pemfigus foliaseus, PVg: Pemfigus vejetans, BP: Büllöz pemfigoid, EB: Epidermolizis bülloza, DH: Duhring hastalığı, SP: Skatrisyel pemfigoid

Tablo 3. Histopatolojik özellikler (\%)

\begin{tabular}{|l|l|l|l|l|l|l|l|}
\hline & PV & PF & PVg & BP & EB & DH & Hailey-Hailey \\
\hline Suprabazal ayrısma & $14(\% 40)$ & - & - & - & - & - & - \\
\hline Akantoliz & $2(\% 5,7)$ & - & $1(\% 50)$ & - & $1(\% 7,1)$ & - & $1(\% 100)$ \\
\hline $\begin{array}{l}\text { Intraepidermal bül olu- } \\
\text { şumu }\end{array}$ & $7(\% 20)$ & $4(\% 100)$ & - & $4(\% 12,5)^{*}$ & - & - & - \\
\hline Subepidermal ayrışma & $3(\% 8,6)$ & - & - & $10(\% 31,3)$ & $1(\% 7,1)$ & $4(\% 100)$ & - \\
\hline $\begin{array}{l}\text { Perivasküler eozinofil } \\
\text { infiltrasyonu }\end{array}$ & $1(\% 2,9)$ & - & - & $2(\% 6,3)$ & - & - & - \\
\hline \begin{tabular}{l} 
Dermoepidermal ayrışma \\
\hline
\end{tabular} & - & - & - & $11(\% 34,9)$ & $4(\% 28,6)$ & - & - \\
\hline
\end{tabular}

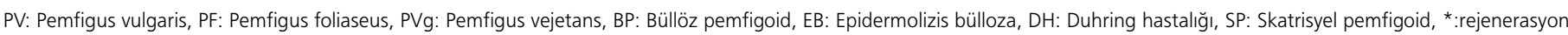
bülümü

bu olgularda saptanmadı. PF'li olguların \%25'inde DiF negatifti. PVg için \%50 olguda DiF negatifti. BP'li \%40,6 olguda bazal tabakada IgG birikimi, \%3,1 olguda bazal tabakada C3 birikimi saptandı. Olguların $\% 40,6$ 'sında Dif negatifti ve \%15,7'sine de biyopsi yapılmadığı saptandı. DH için \%100 olguda bazal tabakada granüler Ig A saptandı. Birikim saptanmayan olgularımızda tanı klinik ve histopatolojik bulgulara göre konulmuştur. Biyopsi ve tanı doğrulaması yapılamamış olgular klinikle değerlendirilmiştir. EB'li olguların tümü HEB olarak değerlendirildi. Aile öyküsü olması, biyopsi ve klinik uygunluğu, DiF'te birikim olmamasıly tanı aldılar. PNP ve IgA pemfigusu tanısı alan olgumuz bulunmamaktadır. BP'li olguların \%37,5'inde hastalığın ortaya çıkısı ile ilaç kullanımı arasında ilişki saptandı ve olguların $\% 66,6$ 'sında hastalığın başlangııından önce hastalığa neden olabilecek veya tetiklenmesine yol açabilecek tiazid grubu diüretikleri kullandıkları saptandı. PV'li iki olguda hastalık gebelik ile ortaya çıktı.

Büllöz hastalığı olan 93 olgunun \%20,4'ünde hipertansiyon (HT), \%12,9' unda diabetes mellitus (DM) mevcuttu. Bir PV, bir BP ve bir HEB olgusunda psoriazis vulgaris eşlik eden dermatozdu.

PV'li olguların \%14,3'ü sistemik steroid, \%80'i sistemik steroid ile birlikte adjuvan ilaç ile tedavi edildi. Olguların \%68,6'sında azatiyoprin, $\% 20$ 'sinde metotreksat, \%8,6'sında mikofenolat sodyum adjuvan ilaç olarak kullanıldı. Bir PV'li olguya plazmaferez yapıldı. PV'li olguların sadece ikisinde azatiyoprin kullanıldı. BP'li olguların \%50'si sadece sistemik steroid, \%31,3'ü sistemik steroid ile birlikte adjuvan ilaçla tedavi edildi. En sık kullanılan adjuvan ilaç \%25 olguda azatiyoprindi. İki BP olgusunun birinde tetrasiklin, birinde dapson tedavisiyle iyileşme sağlandı. DH'li tüm olgulara dapson tedavisi verildi. Bütün olgulara sistemik tedavilerinin yanında lokal yara bakımı yapıldı.

Tedaviye başlandıktan sonra pekiştirme fazı PV'li olgularda ortalama 21,7 gün, BP'li olgularda ortalama 12,6 gündü. HEB'li olgularda iyileşme ve nüks değerlendirilemedi. PV'li olguların \%42,9'unda ortalama 27,9 ayda tedavi altında iyileşme varken alevlenme saptandı. BP'li olguların \%81,3'ünde tedavi altında iyileşme varken alevlenme olmadı. PV ve buna bağlı komplikasyonlar nedeniyle 5 olgu kaybedildi. kaybedildi; fakat bu olguların verileri uygun olarak kaydedilemediği için 93 olgu içine dahil edilemedi. BP nedeniyle ölen olgumuz bulunmamaktadır.

Tedaviye bağlı en sık görülen yan etkiler; PV'li olguların $\% 48,6$ 'sında DM, \%34,3'ünde HT, \%42,9'unda hiperlipidemi, \%22,9'unda oral kandidiyazis, \%17,1'inde osteopeni, \%11,4'ünde Cushingoid görünüm, \%2,9'unda femur başı aseptik nekrozuydu. BP'li olguların \%31,3'ünde DM, \%25'inde HT, \%18,8'inde hiperlipidemi, \%6,3'ünde osteopeni, \%3,1'inde pulmoner emboli saptandı. 


\section{Tartışma}

Çalışmamızda en sık görülen otoimmün büllöz hastalık PV idi. Avrupa'da en sık görülen otoimmün büllöz hastalık BP iken Türkiye'de Akdeniz bölgesinde 148 olguyu içeren bir çalışmada PV'in en sık görülen otoimmün bülloz hastalık olduğu bildirilmiştir4. PV'nin ortaya çıkış yaş ortalaması Ege bölgesinde 48,3, Akdeniz bölgesinde 43 olarak saptanmıştır4,5. Olgularımızda PV'nin ortaya çıkış yaş ortalaması 45,9 yıldı.

Pemfigus grubu hastalıklar sıklıkla kadın ve erkekleri eşit oranda tutar6,7. Türkiye'de PV kadınlarda daha sık gözlenmektedir (K/E: 1.35/1). Bu dağılım çeşitli genetik ve hormonal faktörlerle açıklanmaya çalışılmıştır ${ }^{4}$. Konya'da tanı koyduğumuz PV'li olguların 21'i (\%60) kadın, 14'ü (\%40) erkekti. Olgularımızda K/E: 1,5/1'di. Gebelik ile ortaya çıkan pemfigus nadir gözlenmektedir8. Çalışmamızda iki PV'li olguda hastalığın gebelik döneminde ortaya çıktığı saptanmıştır.

PV'te oral mukoza tutulumu olmadan sadece deri tutulumu nadirdir9. Ege bölgesindeki PV'li olguların \%28,8'inde, Akdeniz bölgesindeki PV'li olguların \%82,1'inde hastalığın oral mukoza tutulumu ile başladığı bildirilmiştir4,5. Çalışmamızda; PV'li olguların \%57,1'inde hastalık oral mukozadan başlamıştı. PV, oral mukoza tutulumu ile başladığında tanı gecikebilir. Ege bölgesinde oral mukoza tutulumuyla başlayan olgularda tanıya kadar geçen süre 6 ay, oral mukoza ve deri tutulumu ile başlayan olgularda 3,7 aydır ${ }^{5}$. Çalışmamızda; oral mukoza tutulumu ile başlayan PV'li olgularda bu süre 14,2 ay, deri tutulumu ile başlayan PV'li olgularda 4,4 aydı. Sadece oral mukoza lezyonları olan olgularda bu sürenin uzun olması; oral lezyonların diğer mukozal hastalıklarla karışarak tanı almasının gecikmesine, doktorların ve/veya olguların eğitim eksikliğine, sosyokültürel seviye düşüklüğüne bağlandı. PV'de tırnak tutulum sıklığı \%34,2 - 38 olarak belirtilmiştir. Tırnak tutulumu hastalık aktivasyonu ile korele olabilir. PV'de tırnak tutulumu akut ve kronik paronişi, onikomadezis, Beau çizgileri, subungual hemoraji, subungual hiperkeratoz, trakionişi, pitting, sarı renk değişikliği ve onikolizis şeklinde görülebilir. PV'de paronişi ve onikomadezis en sık saptanan tırnak bulgularıdır10. PV'li olgularımızın \%11,4'ünde onikomadezis mevcuttu.

Pemfigus, kaptopril ve penisilamin gibi desmogleinlerin sülfidril grupları ile çapraz reaksiyon veren ilaçlarla ortaya çıkabilmektedir6,11. PV'li bir olgumuzda hastalık tiazid grubu diüretik kullanımı ile başlamıştı. Pemfigus grubu hastalıklara nadiren timoma, myastenia gravis, sistemik lupus eritematozus ve BP eşlik edebilir6,12. Çalışmamızda PV'li olgularımıza en sık eşlik eden hastalık; dört olguda HT, beş olguda ise tip 2 DM idi.

Pemfigusun sistemik tedavisinde yüksek doz steroid altın standarttır ${ }^{13}$. En sık tercih edilen adjuvan ise azatiyoprindir4,14,15. Olgularımızın $\% 80$ 'inde sistemik steroid ile birlikte adjuvan kullanıldı. En sık seçtiğimiz adjuvan ise \%68,6 olguda azatiyoprindi. İki olguda sadece azatiyoprin kullanıldı. Literatürler tarandığında; PV'in iyileşme sürelerinin tanı sonrası \%25 olguda 2 yıl, \%50 olguda 5 yıl, \%75 olguda 10 yıl içinde gerçekleştiği saptanmıştır ${ }^{15}$. Türkiye'den bildirilen yayınlarda PV'de Akdeniz bölgesinde tam iyileşme \%39,4 olguda ortalama 9 aydır4. Çalışmamızda PV'li olguların \%42,9'unda ortalama 27,9 ayda tedavi altında iyileşme varken alevlenme saptandı. Pemfigusta sistemik tedavilere bağlı olarak gelişen yan etkiler en sık DM, HT, hiperlipidemi, oral kandidiazis ve diğer infeksiyonlar, osteoporoz, katarakt, femur başı aseptik nekrozudur ${ }^{4}$. Çalışmamızda olguların \%48,6'sında DM, \%34,3'ünde HT, \%42,9'unda hiperlipidemi, \%22,9'unda oral kandidiazis, \%17,1'inde osteopeni, \%11,4'ünde Cushingoid görünüm, bir PV'li olguda femur başı aseptik nekrozu saptandı.

BP sıklıkla 60-80'li yaşlarda görülen otoimmün büllöz hastalıktır7,13. Olgularımızda BP'nin ortaya çıkış yaş ortalaması 70 iken $\mathrm{K} / \mathrm{E}$ oranı 1,67/1 idi. Oral mukoza tutulumu \%10-35 olarak bildirilmiştir6,13,16. Çalışmamızda; olguların \%12,5'inde hastalık oral mukozadan başlarken, \%3,1'inde sadece oral mukozada sınırlı kalmıştır. Olguların \%75'inde ise hastalık sadece derite dağılım göstermekteydi. BP'e psoriazis gibi dermatozlar eşlik edebilir17,18. Bir olgumuzda BP ve psoriazis vulgaris birlikteydi. BP ilaçlardan en sık penisilamin ile tetiklenir11,19. Çalışmamızda BP'li olguların \%37,5'inin ilaçlarla (8 olguda tiazid, 2 olguda amlodipin, 2 olguda penisilin) ile tetiklendiği saptandı.

Lokalize hastalıkta lokal steroidler etkilidir. Yaygın hastalıkta sıklıkla sistemik steroid ve diğer adjuvanlar tedavide kullanılmaktadır6,20. Olguların \%62,5'inde sadece sistemik steroid, \%25'inde sistemik steroid ile birlikte adjuvan olarak azatiyoprin kullanıldı. Bir olguda sadece tetrasiklin, bir olguda sadece dapson kullanıldı. BP'te spontan iyileşme süresi 3-38 ay olarak belirtilmiştir ${ }^{19}$. Tedaviye başlandıktan sonra pekiştirme fazı BP'li olgularda ortalama 12,6 gündü. Olguların $\% 18,8^{\prime}$ inde ortalama 12,8 ayda tedavi altındayken alevlenme saptandı. Tedaviye bağlı en sık görülen yan etkiler; olguların \%31,3'ünde DM, \%25'inde HT, \%18,8'inde hiperlipidemi, \%6,3'ünde osteopeni, bir olguda ise pulmoner emboliydi.

Sonuç olarak çalışmamızda; Konya ilinde en sık PV, ikinci sıklıkta BP görülmektedir. PV'nin ortaya çıkış yaş ortalaması 45,9 yıldır ve kadınlarda daha fazla görülmektedir. PV'li olgularda hastalık oral mukozadan başlayıp diğer coğrafik bölgelere göre; oral mukoza tutulumu ile başlayan PV'li olgularda tanı alma süresi daha uzundu. BP'nin ortaya çıkış yaş ortalaması 70 yıl olup ve kadınlarda daha fazla görülmektedir. Olguların \%12,5'inde hastalık oral mukozadan başlamaktadır. Tedavilere bağlı görülen yan etkiler en sık pemfigus vulgarisli olgularda saptandı. Ayrıca çalışmamız; ülkemizin önemli bir coğrafik bölgesinden büllöz hastalıklarla ilgili elde edilen ilk veriler olması nedeniyle, ileride bu konuda, bu bölgeden yapılacak olan epidemiyolojik çalışmalara temel oluşturması açısından literatüre yararlıdır. Ilimizde, oral mukoza hastalıkları tanı ve ayırıı tanı açısından mezuniyet sonrası eğitimlerin faydalı olacağını düşünmekteyiz. Ülkemizle ilgili tamamlanmış çok merkezli çalışmaların olmamasından dolayı büllöz hastalıklarla ilgili detaylı epidemiyolojik çalışmaların yapılması önem arz etmektedir. Olguların bir kısmına biyopsi yapılmamış olması, immünfloresan dışında doğrulama testlerinin kullanılmamış olması, HEB'li olguların tanısında bir kısım olguya biyopsi yapılamaması ve biyopsi yapılabilenlerde de elektron mikroskobik inceleme ile alt tiplendirme yapılamamış olması çalışmamızın sınırlııılarıdır.

\section{Kaynaklar}

1. Daneshpazhooh M, Chams-Davatchi C, Payandemehr P, Nassiri S, Valikhani M, Safai-Naraghi Z: Spectrum of autoimmune bullous diseases in Iran: a 10year review. Int J Dermatol 2012;51:35-41.

2. Fine JD: Epidermolysis Bullosa. Dermatology. Ed. Bolognia JL, Jorizzo JL, Rapini RP, et al: 2nd ed. New York. Mosby Elsevier, 2008;457-66.

3. Hohll D, Mauro T: Darier Disease and Hailey-Hailey Disease. Dermatology. Ed. Bolognia JL, Jorizzo JL, Rapini RP, et al. 2nd ed. New York. Mosby Elsevier, 2008;791-800

4. Uzun S, Durdu M, Akman A, Gunasti S, Uslular C, Memisoglu HR, Alpsoy E: Pemphigus in the Mediterranean region of Turkey: a study of 148 cases. Int J Dermatol 2006;45:523-28

5. Bozdag K, Bilgin I: Epidemiology of pemphigus in the western region of Turkey: retrospective analysis of 87 patients. Cutan Ocul Toxicol 2012;31:280-5. 
6. Stanley JR: Pemphigus. Fizpartrick's Dermatology In General Medicine Ed. Wolff K, Goldsmith LA, Katz SI, et al. 7th ed: New York, McGraw-Hill, 2008:459-68

7. Parker SR, MacKelfresh J: Autoimmune blistering diseases in the elderly. Clin Dermatol 2011;29:69-79.

8. Kardos $M$, Levine $D$, Gürcan HM, Ahmed RA: Pemphigus vulgaris in pregnancy: analysis of current data on the management and outcomes. Obstet Gynecol Surv 2009;64:739-49.

9. Turgutalp SÇ, Harman M: Dicle Üniversitesi Tip Fakültesi Dermatoloji Polikliniğine Başvuran Pemfiguslu Hastaların Klinik Özellikleri. Dicle Tıp Dergisi 2007;34:116-9.

10. Habibi M, Mortazavi $\mathrm{H}$, Shadianloo $\mathrm{S}$, et al: Nail changes in pemphigus vulgaris. Int J Dermatol 2008;47:1141-4.

11. Kneisel A, Hertl M. Autoimmune bullous skin diseases Part 1: Clinica manifestations. J Dtsch Dermatol Ges 2011;9:844-56.

12. Ljubojevic S, Lipozeni J: Autoimmune bullous diseases associations. Clin Dermatol 2012;30:17-33.

13. Sticherling $M$, Erfurt-Berge C: Autoimmune blistering diseases of the skin Autoimmun Rev 2012;11:226-30.
14. Hofmann SC, Kautz O, Hertl M, Sticherling M, Zillikens D, Bruckner-Tuderman L: Results of a survey of German dermatologists on the therapeutic approaches to pemphigus and bullous pemphigoid. J Dtsch Dermatol Ges 2009;7:227-33.

15. Coronel-Pérez IM, Rodríguez-Rey EM, Pérez-Bernal AM, Camacho FM: Epidemiology of pemphigus in the Hospital Universitario Virgen Macarena, Seville, Spain 2005-2006. Actas Dermosifiliogr 2009;100:121-5.

16. Patrício P, Ferreira C, Gomes MM, Filipe P: Autoimmune bullous dermatoses: a review. Ann N Y Acad Sci 2009;1173:203-10.

17. Gunay U, Gunduz K, Ermertcan AT, Kandiloğlu AR: Coexistence of psoriasis and bullous pemphigoid: remission with low-dose methotrexate. Cutan Ocul Toxicol 2013;32:168-9.

18. Cusano F, lannazzone SS, Riccio G, Piccirillo F: Coexisting bullous pemphigoid and psoriasis successfully treated with etanercept. Eur J Dermatol 2010;20:520.

19. Akay BN, Bodamyalı P, Sanlı H, Akyol H: Büllöz pemfigoidli hastalarda 10 yıllık gözlem. Turkderm 2010;44:61-4.

20. Meurer M: Immunosuppressive therapy for autoimmune bullous diseases. Clin Dermatol 2012;30:78-83. 